\title{
The Role of CLOUD in FinTech and RegTech
}

\author{
Dubey Vivek $^{\star}$, Sonar Rakesh ${ }^{\star \star}$, Rohit S. Walimbe ${ }^{\star \star \star}$, Anindya Mohanty ${ }^{\star \star \star \star}$
}

\begin{tabular}{l}
\hline \multicolumn{1}{c}{ A R T I C L E I N F O } \\
\hline Article history: \\
Accepted November 2020 \\
Available online December 2020 \\
\hline JEL Classification \\
G20, G21 \\
Keywords: \\
RegTech, FinTech, Cloud, \\
Smartphone Banking, Artificial \\
Intelligence
\end{tabular}

\section{Introduction}

Currently, many financial institutions are developing and testing cloud-based services and above all few have opted to use the shared services that has been made available by Big Tech giants, for example, Amazon has been convincing important entities about the security of using their shared storage for at least couple of years. Still, entities are opting for a very cautious stance regarding migration of their central banking system to the cloud. Though Financial Institutes understand that there will be ease of use with reduced cost reduction if they use Cloud infrastructure with relevant services. Financial institutions that want to remain competitive with respect to Technology, precisely Regtech or "cloud-native" companies, must have a clear understanding of why changes in the user behavior requires that the infrastructure be in the cloud.

Technology companies are eating up the ground for banking by entering virtually all financial services verticals (savings products, loans, and payments) and are doing so in a fast, inexpensive, and customer-oriented manner and one of them is Cloud migration approach. Regtech companies, on the one hand, create well-designed applications by attracting customers by creating new channels, and on the other hand, they outsource basic financial services that require capital to a partner bank or other financial services company (eg, lending platforms, credit line facility, etc.). Additionally, they automate manual processes obtaining low cost solutions. Although banks are migrating some surface systems to the cloud and many of their applications are hosted by third parties or managed in the hybrid cloud, the incompatibility generated by the new front-end with outdated infrastructure makes it impossible to respond to new customer needs.

Since 2010, entities have cut their expenses on average by 18\%, cutting personnel costs and the network of physical offices (and consequently legal expenses), and the profitability per employee has increased by $57 \%$. Therefore, entities have reached a point where a greater cut in personnel would negatively influence their profits. According to experts, investing in IT has a greater impact on the profitability of the company through the strategy of using it to increase revenue than to simply cut expenses. Conferring to estimates, $80 \%$ of current IT spending goes to maintaining current systems and migrating to the cloud would help directly the savings produced to the new innovation. Therefore, the advantages of migrating operations to the cloud go beyond cost savings since it enables the redistribution of these savings to innovation, reinforces alliances with cloud service providers, improves system efficiencies and allows entities are positioned in a good situation to face the unpredictable future in terms of new competition and regulatory changes.

^Insights \& Data Practice, Capgemini, United Kingdom, ${ }^{\star \star}$ Insights \& Data Practice, Capgemini, United Kingdom, ${ }^{\star \star \star}$ Digital Engineering Excellence Practice, Capgemini, United Kingdom, ${ }^{\star \star \star}$ Insights \& Data Practice, Capgemini, United States of America. E-mail address: arryan.vivek@gmail.com (D. Vivek - Corresponding author)

\begin{abstract}
A B S T R A C T
The paper advances the theme of the digital disruption arising in the financial industry that
has formed a boom in new alliances connecting fintech companies and banking institutes. It is the latter that has to deal with the abundance of regulations by control entities, in regulators in different countries have had to face a dilemma: evolve or fight. This dilemma has induced financial institutions to now have an extensive volume of data collected from
their users, which must be processed and evaluated to ensure that they comply with the regulatory requirements of control entities. It is focused on the discussion around the value
of data being made available on the Cloud and its usage right from - making simple bank statements available on the Cloud to Image processing against the legal documents, digital
authority, and photos available worldwide for identification and verification process. It also touches upon the value of digital signature in the time of COVID 19. In the end, it
\end{abstract} management and compliance of financial institutions. .

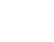


If we compare the different implementation models, regulators do not oppose the environment managed by a third party as long as they adhere to current security measures, data privacy, etc. UK financial authorities (FCA) announced in July the measures that cloud service providers had to comply with and did not oppose the use of the cloud if the services were implemented in a consistent way like any private cloud infrastructure (On-premise) and whether the financial institution continued to hold all regulatory responsibility.

Service providers have addressed deficiencies in their systems so that entities could truly consider handing over their core operations to the cloud. Entities now own and can manage encryption keys which are essential for storing customer personal data in external environments. Also the mentality and strategies regarding cyber-security are changing which has opened the door to public clouds. The popularity of open standards is also alleviating the fear of moving services to the cloud. Industry standards that are supported by both financial institutions and technology companies contribute to the design of cloud infrastructures and are reducing costs.

Talking about Innovation, digitization and the new paradigm in the world of Financial Services is no longer something new or future but, quite the contrary, it is something current and present that we see daily through different media and forms. It is more than known that the financial services industry is currently witnessing in many cases and participating in a few others, an incremental wave of innovation and the appearance of new actors that have generated (and are generating) new business models that in turn deepens. beyond.

The objective of this paper is to focus on the role of Cloud in FinTech and RegTech in 2020 and

\section{Requirement of Regulators as per the new-age technology stack}

It is a business in full growth as evidenced by recent quarterly results from industry leaders, AWS (Amazon) or Azure (Microsoft), with double-digit growth in their operations. In recent years, any company even SMEs- and from any productive sector that wants more flexibility, agility and lower costs has opted for the resources offered by the cloud. The reasons are very diverse and - probably - go far beyond allowing the massive archiving of documents and being a quick way to share them in a digital way. Reducing the operational cost exponentially by using statements and official documents digitally available on the Cloud instead of traditional way of operations that includes paper print, postage cost, and the human resource. This is the most basic step to start with, for any organization. For this reason, state agencies are also betting on its use in their different organizations. The second most important issue is the customer communication chats, or complaints that were through the telephony channel, stored randomly in the form of files to be upgraded to the Cloud platform. After achieving first two basic steps, financial institutes may go ahead with digital KYC along with identification and verification, digital contracts signature and many more.

The European Commission has launched within the European Digital Agenda, the strategy to "Unlock the potential of cloud computing in Europe". This program seeks to accelerate and increase the use of 'cloud computing' throughout the economy, boosting European companies and the productivity of public administration. For all of them, the use of the cloud in recent times is increasing and some studies indicate a level of adoption of more than $50 \%$ in the combined small and medium-sized companies in the US. For all these reasons, it is convenient to review the reasons and advantages of cloud use among companies.

\subsection{Main Advantages - Obvious Ones}

\section{Mass Storage Mass storage}

This is one of the main - and most obvious - reasons for using cloud computing. The number of files of different formats that we handle increases every day. Companies work with graphic documents, with presentations, with prototypes, etc. and require storage systems with large capacities.

\section{Security}

Cloud computing companies are investing large amounts in security and that is why they are a good bet in that field. The truth is that even a medium-sized company can hardly invest an exorbitant amount in security.

\section{Availability}

Another reason to use cloud computing is to be able to access all the files from the office, the house, or the beach ... It is perfect for companies with employees who do not occupy fixed positions and even for companies with several branches in different areas or cities. We live in a time when teleworking is a way to achieve family reconciliation and the cloud can help a lot to take advantage of it. 
In addition, by improving accessibility and mobility, the cloud model improves the agility or competitiveness of a company and its way of working. With its use, file dynamics are generated that are very difficult to achieve with the traditional model. The cloud increases collaboration, makes teams better connected, and can work on shared documents and applications simultaneously. It allows tracking the business of the day in real time.

\section{Cost savings}

Cloud computing companies offer services that are paid according to consumption, that is, month by month. This means that it is not necessary to pay an initial amount to use it. The use of the cloud also entails less infrastructure and maintenance, than in the case of companies with "more outdated" systems, raising the bill for fixed expenses.

\section{Automatic update}

Cloud computing providers are responsible for all server maintenance and security updates. Any update is normally also notified to the client, but they do not have to make new investments.

\section{Flexibility}

Businesses can choose the cloud computing services that best suit their needs. All they have to do is pay for the service over the Internet and they can start using it. Many services also offer a free trial period and expansion possibilities, so when you need more capacity, you can hire more and when you need less, you hire less and only pay for what you use.

\section{Freedom}

More than a reason in itself, at this point all of the above could be included and summarized but in a more abstract way. The cloud is much more than a tool that allows you to store files and other technological benefits. The cloud changes the operation of a company giving it freedom, but always having control of all resources (see COWNURN ET AL, 2019).

\subsection{Main Advantages - Innovative Ones}

\section{Digital Identification and Verification and KYC}

Best part of cloud services where on the spot image processing is done with the legal documents, photos available on cloud to identify and verify the person along with relevant information to Know Your Customer better.

\section{Digital Signature}

Another one is the digital signature from any part of the world and making document available for others to use, making ease of business and reducing operational cost. Though it is a one-time investment towards Artificial Intelligence, Internet of Things but still a profitable innovative approach to stay in market ahead of others.

\section{Digital Payments}

Digital payments are increased by a significant percentage over the years and the whole world has seen the digital payment acceptance during ongoing Pandemic situation. With the compliance alignment user is enjoying purchase/sell across the globe. That's the influence of digital payments powered by cloud infrastructure.

\section{Banking Through Smart Speakers}

Financial Institutes and Tech Giants are investing heavily in Banking through Voice Biometrics that is through the IOT devices like Smart Speakers. Banking through Smart Speakers will again be the gamechanger and will give rise to massive Cloud infrastructure initiatives.

\section{How Regulators are using cloud for regulatory reports?}

Cloud computing is defined by the United States National Institute of Standards and Technology as "ubiquitous, convenient and on-demand network access to a group of configurable computing resources (e.g., networks, servers, storage, applications, and services) they can be delivered and published quickly with minimal management effort or supplier interaction". Moving operations to the cloud is attractive for companies because in exchange for investing in physical goods, you can purchase subscriptions to these types of services and make monthly or annual payments. Additionally, the associated payment is determined according to the amount of data and the number of users who will make use of the service, facilitating the possibility of increasing or decreasing operations based on their needs. For the financial sector, cloud 
computing infrastructure has materialized as an opportunity to evolve operating processes towards more efficient solutions. Likewise, the market has seen the emergence of so-called fintech, which have eliminated friction for customers by offering them fully digital financial services at little or no cost from platforms supported entirely by cloud services. For this type of digital tools, the information of natural agents or companies is delivered to a third party for storage and processing.

Furthermore, the person offering the service does not necessarily have to reside in the same country as the person hiring it. Due to the nature of this type of services, their massive use represents a significant challenge for governments in terms of data protection, consumers, jurisdictions and judicial investigations, which is why countries around the world have regulations that limit, guide and promote the use of cloud computing. Colombia is the third largest ecosystem of fintech startups in Latin America, and given the initiative of the Financial Superintendence of Colombia to regulate the use of cloud computing services by financial entities, through a project of an external circular, the development of regulation on this type of services at an international level. China, the European Union, the United States and Brazil are taken as an example, in order to provide considerations on the rules that define the use of these services in our country (see ANGNOSTOPOULOS, 2018).

\section{Regulators are getting accustomed with FinTech in 2020 and making New Regulation Reports using cloud}

Digital innovation has strongly broken into the world of finance, generating new business models that cause a disruption with respect to the traditional banking organization model. Digital disruption is challenging the traditional way of offering financial services to companies in more agile, flexible, transparent and economic ways. It is the FinTech phenomenon, which comes from the union of the English words Finance and Technology, and refers to startups that use the latest technologies to offer innovative financial services. FinTech companies, therefore, are companies that create disruptive business models in the financial services industry. According to Huete (2018), for a company to be considered FinTech, it has to develop a groundbreaking and at the same time renovating business model, within the financial services industry. The Basel Committee on Banking Supervision defines the term FinTech as "Technologically enabled financial innovation that results in new business models, applications, processes, or products with an associated material effect on financial markets, institutions, and the provision of financial services".

Therefore, it can be said that the main objective of FinTechs is to create innovative products or services in a traditional sector to improve their efficiency in terms of management, processes or business resources. Thus, companies have access to different applications or digital tools, in a simpler, friendlier and accessible way at any time or place (Bonilla, 2017). From the Financial Digitization Observatory created in early 2017 by the Foundation of the Savings Banks (Funcas) and the consultancy KPMG (ODF, 2017a) they affirm that it is not a passing fad because, in an increasingly context Technological and digitized, customers demand a different way of managing their finances, according to this new environment. The rise of these companies around the world is nothing more than a reflection of the technological tsunami, which has already devastated other industries, such as the music industry or the media (eg music or streaming television) and which is now it will also profoundly affect the financial services industry. Although the origin of the FinTech sector predates the financial and banking crisis that started in 2007, the crisis has meant a fundamental disruption to understand the FinTech phenomenon.

This is because it has brought about a significant change in the way banks relate to their service providers and their customers. The discontent of many users towards banks has served as a focus of cultivation so that FinTech initiatives are being developed in various areas and in different geographical areas. FinTech startups are characterized because they are born focused on offering a specific financial service, that is, it is about being a micro-segmented market at least in the initial stages of FinTech companies. This characteristic is an important difference from the traditional financial sector in which few companies offer a wide range of financial services. In turn, as they are online businesses, they do not generate the costs that they generally bear, and consequently, they are passed on to their clients, traditional financial institutions. These startups have been able to take advantage of some shortcomings with respect to the payment system or investments and have achieved very agile and attractive solutions, thanks largely to the micro-segmentation of their products and mobility (see RYANA ET AL).

About 80 percent of Chinese banks will buy and integrate fintech solutions in the cloud by 2024, according to global market intelligence firm International Data Corporation (IDC). The latest report on China's digital financial transformation, released by IDC, notes that the Asian country has actively adopted a new generation of computing technologies such as cloud computing, big data, artificial intelligence, mobile internet and internet of things. Spending in the information technology sector is expected to continue expanding and reach 220.8 billion yuan (about $\$ 31.61$ billion) by 2020 , according to the report.

IDC anticipates that 20 percent of bank transactions will be settled in advance through digital platforms by the end of 2020, based on the integration of digital and physical experience. According to the report, about 30 percent of China's insurers will cooperate with at least three insurance technology companies by 2021, while 40 percent of the country's banks will cooperate with financial technology 
companies in the ecosystem of the cloud ahead of 2022. By the end of 2022, 35 percent of insurance companies will use artificial intelligence and voice interaction technology to automate the claims settlement process, the report said.

The current circumstances mean that today the electronic signature has an unprecedented relevance and those banks and financial institutions have to adopt it in all areas, from customer-facing transactions to B2B and internal processes. Likewise, today with social distancing, branches are leveraging the electronic signature as part of a branch transformation initiative. Others start on the online channel with high-volume, self-service transactions (see CHANG AND JINMIAO, 2018).

\section{Regulators are getting more insights [Darkweb, digital KYC, AI based fraud control] by using Cloud}

The Fintech Festival in Singapore is one of the most important events in the sector worldwide. Gradiant was in the Spanish pavilion, where he wanted to present his new solution to prevent document fraud and biometric verification as a form of customer identification. In this event that last year managed to gather almost 45,000 participants from 130 countries, the Spanish company has presented forensic analysis and facial recognition technologies to safely automate the processes of digital onboarding and Know Your Customer (KYC), as well as to prevent documentary fraud on the Internet. With this technology, Valida has been developed, a forensic tool for the detection of manipulations in digital documents.

Valida's objective is to assess the authenticity of digital documents to prevent fraud in the online and digital onboarding KYC user verification processes. With these tools companies can increase the level of security when corroborating certain identification documents of users and clients. Valida can automatically analyze any type of document in PDF and JPEG format (DNIs, passports, payrolls, invoices, receipts, etc.), detecting possible phishing attacks and modifications to the data present in said files (see CHISHTI, 2019).

In addition, the company complements it with algorithms that have been developed for life detection that are incorporated into digital onboarding processes as a second element of authentication, in order to demonstrate that the customer is who he says he is. "Our proposal focuses on taking advantage of the digital onboarding process to collect other information that provides us with a higher level of security in its verification, such as your signature, your voice or a video," explains González-Jiménez, director of the department of Gradiant Multimodal Information. "We have these three biometric technologies and we can implement them together or separately (see KAVASSALIS ET AL, 2018)."

\section{With FinTech the definition and nature of Regulation reports are changed during 2020 pandemic}

The importance of 'fintech' regulation, a consequence of the digital transformation, does not understand borders: in Europe, both the European Commission and the European Banking Authority (EBA) published their action plans in mid-2018, setting a roadmap until mid-2019. Despite the fact that these reports or laws have completely different contexts and situations, they can establish common denominators for all of them, as detailed by BBVA Research in its report:

In the payments environment, the great milestone of 2018 has been the entry into force of the new Payment Services Directive (PSD2), which seeks to promote competition and strengthen the security of payments in Europe. To do this, it regulates access to clients' payment accounts by third parties, who may offer information aggregation services and initiate payments. During the year the authorities have continued to work on defining the technical details.

Regulations on access, use and protection of data: During the last year, the value of data has become a strategic asset in the digital economy. This leads to attractive value propositions being created for customers, but in turn increases privacy concerns. The recently approved Fintech Law regulates the accessibility and the right to data portability.

Cybersecurity: the increase in the frequency and sophistication of cyber-attacks explains why in 2018 work continued to improve harmonization and international cooperation. Cybersecurity was at the center of the agenda of the European Commission and the European Central Bank in 2018.

Competition in the era of 'bigtech' companies: During 2018, the public debate on the role of large technology companies in the digital economy and in the financial sector has intensified. This trend is expected to continue in 2019 (see BENG ET AL).

\section{Contactless Payment and KYC are based on AI and Cloud}

Credit card security has been evolving in recent years, currently more than $90 \%$ of merchantenabled POS terminals in Peru can receive contactless payments, according to Asbanc.

However, the habit of use is not widespread among users, who still prefer to deliver their card in stores. Australia is one of the most advanced in this, as $90 \%$ of its credit payments were made without contact. "Payment with Contactless cards is done three times faster than a traditional purchase made with cash or a chip card. Debit cards reach a high penetration in the countries of the region and allow to boost contactless payments for day-to-day purchases ", points out the manager of the Division of Personal Banking Products of Banco Pichincha, Julio Rasmussen. Contactless payments will catalyze the adoption and growth of 
digital payments in Latin America and will allow the entry of a next generation of payments, through increasingly popular devices such as bracelets, watches and rings (see TANG, 2019).

According to Americas Market Intelligence, more than 200 countries around the world use contactless cards. It then provides the following security keys for contactless payments.

\section{Approach and pay}

Don't you like to get rid of the card? With contactless payment cards, only you will be the one to manipulate it. You do not need to deliver it. Make the payment of your purchases by approaching your card 4 centimeters from the POS terminal for brief seconds, wait for a 'beep' to sound and the payment will be completed.

\section{Icon without contact}

On the front of your contactless card, you will find the 4 curved bars icon. That icon should approach the POS, every time you make a transaction with your debit card. Say goodbye to swipe the magnetic strips on the cards. To get an idea of the volume that this technology can reach, $50 \%$ of China's GDP is processed through cell phones via QR code (see MACLEAN, 2019).

\section{Less abandonment}

Contactless payment technology allows less abandonment of purchases due to lack of cash. In this way, fewer queues are generated in business and more sales. This is the case in Brazil, the most advanced country in the acceptance of plastic in the region, where there are 2,438 POS terminals per 100,000 inhabitants, although it is still far from the 4,233 POS terminals in the United States.

\section{Ideal for SMEs}

Contactless technology provides benefits to merchants apart from increasing their sales. They can use this type of transaction to ensure fast and smooth check-in payments and increased operational efficiency by reducing cash usage, avoiding data cloning, double purchases, and unintentional purchases.

\section{Zero cash}

In addition to improving the user payment experience, the user will be more secure, because they will carry less cash in their wallet and the lines in stores will be faster.

\section{Pay without password}

It is a very comfortable and safe technology. It is enough to approach the card and you can make a payment, many times even without putting your password.

\section{Bounce}

If the card bounces, it could be due to two situations: the card has insufficient funds or the card does not have the contactless payment icon. In the first case, you could insert the chip into the POS and, if it doesn't work, use another payment method.

\section{Bonus track}

Security: If a customer loses or steals his card, he must immediately notify his bank and from that moment, he will not be responsible for purchases made without his authorization (see PACKIN, 2018).

\section{Enhance the customer experience with customization}

We can use AI to collect data on customer behaviour through each touchpoint of the customer trip. This rich data allows you to create a personalized experience for each client. AI-free companies spend a great deal of time and manpower collecting this data rather than developing a better customer experience. If AI collects the data for you, your team can focus on creating a powerful strategy that improves the customer experience and leads to increased engagement and sales.

\section{Increase conversation rates and ROI}

Email marketing and AI go hand in hand. The AI can analyze the data from your email campaigns and suggest the best times to send emails. It is possible to take this even further and automate emails. Instead of emailing your entire list, you can select different times for people based on their past engagement, demographics, and purchase history. Another way to personalize emails with AI is to use it to recommend products to customers. Keep in mind that personalized email marketing generates an average ROI of $122 \%$. Some companies may be intimidated by implementing AI-powered software. But the truth is, AI is one of the best ways to make your business more efficient and create personalized experiences for your customers at scale. The relationships you build with your customers become the backbone of your business (see MADHUSUDAN). 


\section{Banking through smartphones and regulators are benefiting from the Cloud services}

Regulatory barriers, doubts about its security and adaptation to legacy IT systems have been the major brakes on the consolidation of cloud computing among financial institutions, according to experts from Deutsche Bank. However, increasingly, the main entities address this issue to make their environments more flexible. At the same time, public cloud providers, such as Amazon Web Services or Microsoft Azure, have become more focused on meeting the requirements of this sector. According to Deutsche Bank calculations, "financial institutions make up a quarter of global technology spending and some now say that they will adopt the IaaS model in $20 \%$ or $30 \%$ of its dynamics (especially for development workloads and evidence) within three years, "argue DB researchers Karl Keristead and Ross Sandler." This would represent extraordinary growth, "they point out.

Some, like Capital One, already use AWS for their new mobile banking app, although others, like Bank of America, find no compelling financial incentive for it, David Reilly, his CIO, told Network World in March. The same report concludes that Microsoft may be the most benefited from this growing trend due to its good classic positioning in the sector (see GOUL, 2019).

Much is said about Cloud Banking, as the system that will dominate in the financial sector. This is the data of the banks in the cloud; numbers, accounts, transactions, money orders, document management. The entire relationship between banks and customers is in the cloud. One of the first financial institutions to make this bet was Banco Santander. This company told the Financial Times how it would become a bank that had data storage in the cloud to offer its customers access to new technologies. In fact, according to statements from executives of this bank, the idea of launching this service arose out of the concern of how to compete with new technological players, such as financial startups? The answer to that question was: staying up to date on technological trends, for which they allocated a budget of about USD 3,000 million to develop solutions, according to the note by the Financial Times.

Keeping up to date with new trends and understanding the market is a key to not being left behind in the technological world. A study was recently published saying that digital disruption will take 4 out of 10 companies off the market. To draw this conclusion, 941 business leaders from 12 industries worldwide were interviewed. The results leave a path of innovation that companies must follow to avoid disappearing. One of the most impressive results is that digital disruption will take half of the companies out of the market in the next five years (see BITTNER, 2019).

Luckily there are banks that are thinking about digital disruption and investing so as not to fall behind in the race against startups. In fact, BBVA is another bank that bets on cloud banking, as the Spanish newspaper El Mundo explained. "The banking model has changed radically in just a few years. BBVA customers who use mobile devices (smartphones, tablets and computers) to carry out their usual operations have multiplied by 14 in the last three years and now total 4.3 million at the end of 2015, said the media. That growth only means that every time banks must be alert to these changes and change their business model. That is, leverage on social networks, understand big data as a strategic ally for making better decisions and seeing startups as an opportunity to reinvent them, as was discussed at the \#BancosyStartups conference. And it is that banks are perceived as large and slow elephants that do not react in time to the wave of innovation. For this the reason it is key that all the knowledge of a bank is complemented by the agility of a startup to develop innovative solutions (see ARNER, 2017).

One of the BBVA executives said at a conference that regulating the digital world is key to prevent it from becoming "the wild West" and has recognized that, in banking, "money is data": Data can be transformed into information, information in knowledge, and knowledge in new products. Continuing with cloud banking, or the banking in the cloud, the key is to innovate, but also to understand the regulations of each country. For example, some places allow financial institutions to have the information in the cloud, but it must be physically backed up in the data center. That is, it is a data center in which all the information of a company is. Although the information is in the cloud, there is a physical backup. Another important topic about the cloud is talking about the different actors in payments. It is not only seen in the financial sector, but in music or when ordering food, it ceased to be a relationship of two, since specialized suppliers are included. The services are hosted remotely and payment through the bank requires absolute integration with new technologies so that there is the necessary security in the transaction. On this subject there is still a lot to discuss, because the era of innovation is being lived. The key is for banks to be aware of these changes and have a budget to innovate. Of course, it must be done with a strategic partner that helps them make better decisions to invest resources wisely.

We chat and keep in touch with friends through social networks, we order dinner and go shopping, the smartphone is now an integral part of our daily life. Many innovative and easy to use applications have made our daily activities faster and more comfortable to execute. Even the banking and financial sector has seen the birth of simple and flexible applications that allow the smartphone to manage our checking accounts and bank transactions. Mobile banking is no longer a future trend, but a reality for banks and their users (see BAXTER, 2016). 


\subsection{Understanding mobile banking}

Mobile banking, also abbreviated as M-Banking, covers all financial and banking transactions managed through a mobile device, smartphone or tablet. The term is used regardless of whether the services are used through an Internet browser or an application. In addition, mobile banking is closely linked to the mobile payments sector, such as GooglePay or ApplePay, which allow payments to be made through smartphones without using cash (see CALLEN NAVIGLIA ET AL, 2018).

\subsection{Mobile banking vs. online banking}

What is the difference between mobile banking and online banking? What advantages does the mobile offer bring? Unlike online banking, where you need to start your PC, mobile banking gives you the ability to access services from anywhere with an Internet-enabled device. Mobile use allows users to check the balance, make transfers or manage titles directly from the sofa at home, from a bar, a hotel or anywhere else. With a smartphone or tablet, you always have easy access to the bank. The mobile banking services offered by banks are increasingly adapted to the needs of users. Mobile banking mainly includes three services: account management, banking and capital transactions, information and financial services.

\subsection{The App for mobile banking}

Intuitive, simple and with always new features: applications are the core of mobile banking. Banking and financial services may vary by provider, but generally the main features of a mobile banking application include the ability to check balance and movements, make transfers, set up standing orders, block cards, and manage information. In addition to traditional features, many applications offer additional features, such as finding the closest ATM where you can withdraw cash for free, get automatic notifications to stay up-to-date on important transactions, reminders about important payments, buying and selling stocks, shares and investments or obtain financial information from the exchange. In the future there will be technical developments that will bring additional features to the application to adjust them more and more to the needs of the client (see BUTLER ET AL, 2019).

\subsection{Mobile payment: simple and fast through an application}

Particularly popular with users is the functionality of money transfer through mobile banking. In addition to the usual standard form with name, quantity, IBAN, BIC and object, new innovative payment solutions are proposed. Image captures payments. To complete the payment form, simply take a photo with your smartphone of the invoice or scan the QR code. The application will recognize the relevant data for payment and fill in the corresponding fields. Of course, it will be possible to correct the data if necessary.

\subsection{Pay by chat}

This feature for mobile banking payments work like a messaging service. Simply select a recipient from your contacts and enter the amount to transfer and transaction done (see COLAERT, 2018).

\subsection{Pay for voice commands}

With voice commands you can enter all the necessary fields to make the payment without having to use the keyboard. The services and features of mobile banking are constantly expanding with the latest technological advances and increasingly meet the needs of users.

\subsection{The digital bank and safety measures}

One of the main aspects for those who offer a banking service is certainly security. Mobile banking applications use cryptographic standards such as the 256-bit Advanced Encryption Standard (AES) for data transmission. Some features, such as fingerprint recognition or facial recognition, can be a more secure way than common login data (potentially used by anyone fraudulently) in online banking for a PC (see FCA, 2016).

\subsection{Payment security}

Financial institutions are committed to making online banking a secure medium through login procedures and other technologies. To make a deposit, the TAN procedure is used, a list of number sequences that can be used only once. There are several mTAN features for mobile transfers.

smsTAN: You can receive an mTAN directly through the mobile banking application. The code will be sent directly by SMS to the entered phone number. The security between online and mobile banking is almost comparable.

photoTAN: app2app solution that requires the prior installation and configuration of a photoTAN application compatible with the bank application. During a payment, the mobile banking application will automatically launch the photoTAN application that will confirm and transfer the TAN. 


\section{The Future - Mobile banking backed by Cloud Infrastructure and Services that supports AI and IoT}

In a world where mobility and flexibility become the cornerstone, mobile banking through smartphone or tablet applications has now become the standard for banking and financial transactions. The development of new technologies will make mobile banking increasingly simple, secure and convenient for its users, making it an essential service (see FCA, 2015).

\section{Conclusions}

Considering where the world is going with Digital Banking, Payments, and RegTech, the cloud services are becoming the required anchors to preserve all kinds of information in a secure way, which can be used at any time and maintain a level of security and transparency. For its users, considering that the future of these technologies will continue to advance more and more, and the use of the internet will be necessary for this. Various Cloud services are available to cater financial institute needs in the era of digital banking which is almost like a one click banking through smartphones. Among the different functions that Fintech technologies have, Mobile banking, Big data and predictive models, Compliance, Crowdfunding, Risk Management, Cryptocurrencies, Payments and Transfers and more.

The type of technologies used in the development of solutions is very broad, as explained by the Financial Conduct Authority, the FCA, from the United Kingdom, one of the first entities to carry out a study of its ecosystem. Within Regtech can be found from cloud-based tools, analytics and big data or APIs to the use of artificial intelligence, machine learning, or blockchain. Their popularity in recent times is evident in the volume of money they are moving. Regtech have been present in the startup scene since 2012, and between that year and 2016, they achieved a total of $\$ 2.3$ billion in 317 agreements. Currently, in the first quarter of 2018 alone, investment reached \$ 532.7 million through 33 agreements. In the same period of 2017, 24 agreements had been closed for less than half the money, about 214 million.

There are managerial implications that Cloud Services brings in terms of scalability that connects high volume consumers and producers as required. It also brings in unmatched flexibility for Financial Institutes and the Regulators by providing regulatory reports on demand in realtime. Cloud services have changed the way of Know Your Customer and Identification \& Verification process that has made significant ease of work while managing personal data and in the decision making of loan applications. This whole management is enhanced by RPA and AI-driven approach.

RegTech is the new FinTech, the main difference of the solutions of this type of companies with respect to the previous ones is the agility and speed in their work and their adaptation to the client.

Fintech and Regtech represent an effective opportunity to solve part of the work derived from legal compliance by introducing new age technology stack - Artificial Intelligence, IoT and Cloud Services, through flexible, agile and economic solutions.

\section{References}

1. Anagnostopoulos, I. (2018). Fintech and regtech: Impact on regulators and banks. Journal of Economics and Business, $100,7-25$

2. Arner, D. W., Zetzsche, D. A., Buckley, R. P., \& Barberis, J. N. (2017). FinTech and RegTech: Enabling innovation while preserving financial stability. Georgetown Journal of International Affairs, 47-58.

3. Authority, F. C. (2016). Call for input on supporting the development and adopters of RegTech. FS16/4,(J uly),(accessed September 25, 2018),[available at https://www. fca. org. uk/publication/feedback/f s-16-04. pdf]. [available at https://www. fca. org. uk/publication/feedback/fs-16-04. pdf] (2016)

4. Authority, F. C. (2015). Call for Input: Supporting the development and adoption of RegTech. FCA

5. Baxter, L. G. (2016). Adaptive financial regulation and RegTech: a concept article on realistic protection for victims of bank failures. Duke LJ, 66, 567.

6. BEng, R. V., \& Slagter, M. R. (2017), Standing on the shoulders of RegTech!.."

7. Bittner, B. P. (2019). Discover the Innovative Technology Behind RegTech Leaders. The RegTech Book

8. Butler, T., \& O'Brien, L. (2019). Understanding RegTech for digital regulatory compliance. In Disrupting Finance (pp. 85-102). Palgrave Pivot, Cham.

9. Callen-Naviglia, J., \& James, J. (2018). Fintech, Regtech and the Importance of Cybersecurity. Issues in Information Systems, 19(3).

10. Chang, Y., \& Hu, J. (2018). Research on Fintech, Regtech and Financial Regulation in China.

11. Chishti, B. S. (2019). The Power of RegTech to Drive Cultural Change and Enhance Conduct Risk Management Across Banking. The RegTech Book.

12. Colaert, V. (2018). RegTech as a response to regulatory expansion in the financial sector. Available at SSRN 2677116.

13. Cowburn, N., \& Barnet, P. (2019). RegTech Opportunities in a Post-4MLD/5MLD World. The RegTech Book.

14. Goul, M. (2019, July). Services Computing and Regtech. In 2019 IEEE World Congress on Services (SERVICES) (Vol. 2642, pp. 219-223). IEEE.

15. Kavassalis, P., Stieber, H., Breymann, W., Saxton, K., \& Gross, F. J. (2018). An innovative RegTech approach to financial risk monitoring and supervisory reporting. The Journal of Risk Finance.

16. Maclean, B. (2019). The ROI of RegTech. The RegTech Book.

17. Madhusudan, B. RegTech: The necessary innovation in the regulatory compliance space, available at https://www.the-digitalinsurer.com/wp-content/uploads/2017/10/1002-RegTech-The-necessary-innovation-in-the-regulatory-compliance-space.pdf

18. Packin, N. G. (2018). RegTech, compliance and technology judgment rule. Chi.-Kent L. Rev., 93, 193.

19. Ryan, P., Crane, M., \& Brennan, R. (2020). Design Challenges for GDPR RegTech. arXiv preprint arXiv:2005.12138.

20. Tang, B. B. (2019). Forging a Responsibility and Liability Framework in the AI Era for RegTech. The RegTech Book. 